\title{
Flavone from the Lycopersicon esculentum and their antioxidant capacity through GSH recovery effect
}

\author{
Hyeong-Ju Jeon ${ }^{2}$ (D) $\cdot$ Hyoung-Geun Kim ${ }^{1}$ (D)

\section{토마토(Lycopersicon esculentum)로부터 flavone 화합물의 분리 동정과 세포 내 GSH 희복능을 통한 항산화 활성 평가}

\author{
전형주 ${ }^{2} \cdot$ 김형근 $^{1}$
}

Received: 20 August 2021 / Accepted: 7 October 2021 / Published Online: 31 December 2021

(C) The Korean Society for Applied Biological Chemistry 2021

\begin{abstract}
The fruits of tomato (Lycopersicon esculentum) were extracted with $70 \%$ aqueous methanol $(\mathrm{MeOH})$ and the concentrates were partitioned into ethyl acetate (EtOAc), $n$-butanol $(n-\mathrm{BuOH})$, and water $\left(\mathrm{H}_{2} \mathrm{O}\right)$ fractions. The repeated silica gel $\left(\mathrm{SiO}_{2}\right)$ and octadecyl silica gel column chromatographies for the EtOAc fraction, whose activity was confirmed, led to isolation of one flavone compound. Nuclear magnetic resornance, infrarad spectroscopy, and mass spectroscopy (MS) revealed the chemical structure of the isolated compound, 5,7,3'-trihydroxy-6,4',5'trimethoxyflavone (1). LC-MS/MS analysis determined the content level of compounds $\mathbf{1}$ in the $\mathrm{MeOH}$ extract to be $4.02 \pm 0.12 \mu \mathrm{g} / \mathrm{mg}$ and in the TME-10 fraction to be $0.96 \pm 0.03 \mu \mathrm{g} /$ mg. Through this study, the antioxidantive capacity was confirmed by demonstrating that the $L$. esculentum extract and their fractions showing an increase in glutathione mean and a decrease in glutathione heterogeneity uniformly raises the intracellular glutathione level.
\end{abstract}

Hyoung-Geun $\operatorname{Kim}(\triangle)$

E-mail: zwang05@khu.ac.kr

${ }^{1}$ Graduate School of Biotechnology and Department of Oriental Medicinal Biotechnology, Kyung Hee University, Yongin 17104, Republic of Korea

${ }^{2}$ Department of Food \& Nutrition, Jangan University, Hwaseong, Gyeonggi 18331, Republic of Korea

This is an Open Access article distributed under the terms of the Creative Commons Attribution Non-Commercial License (http://creativecommons. org/licenses/by-nc/3.0/) which permits unrestricted non-commercial use, distribution, and reproduction in any medium, provided the original work is properly cited.
Keywords Flavone · Glutathione recovery · Lycopersicon esculentum $\cdot$ Nuclear magnetic resornance

서 론

토마토(Lycopersicon esculentum)는 가지과의 한해살이풀로, 높 이는 $1.5 \mathrm{~m}$ 정도이며 가지를 많이 내고 흰 털이 난다. 종자에 따라 크게 끝이 뾰족한 형태와, 원반형의 두 종류가 있다. 토마 토는 ascorbic acid, $\beta$-carotene, vitamin $\mathrm{B}$ 군, tocopherol등의 vitamin이 풍부한 것으로 보고되고 있고, 또한 토마토 주요성분 으로는 adenine, trigonelline, choline 및 tomatine이 분리 보고 되어 있다. 특히 lycopene 은 $\beta$-carotene 이상의 항산화능이 있 어, 항암 등 다수의 약리활성이 있는 것으로 알려져 있다[1,2]. 하지만 현재까지 antioxidant 및 anti-aging 효과를 통한 화장품 소재로서의 가능성에 대한 연구 결과는 미미한 수준이다.

Glutathione (GSH)은 glutamate, cysteine, glycine 등의 amino acid로 이루어진 결정성 peptide이자, Reactive oxygen species 에 대한 세포 방어 기전에서 중심적인 역할을 한다[1-3]. GSH 는 세포질에서 생산되어 GSH 산화·환원이 필요한 mitochondria 와 같은 세포 내 소기관으로 전달되며, GSH 농도 유지는 세포 에서 산화, 환원 능력과 신호 전달 체계의 중요한 지표가 된다. 세포 내 GSH 농도가 높을수록 산화적 스트레스로부터 세포를 보호할 수 있고, 노화성 질병을 방지할 수 있다[4]. 최근 살아 있는 세포 내의 GSH 농도를 측정할 수 있는 FreSHtracer라는 가역성 probe가 개발되어[5], 세포 내 GSH 농도와 회복능을 실 시간으로 확인할 수 있다. 노화가 진행되었거나 oxidative stress 가 축적되어 기능이 저하된 세포는 세포 내 $\mathrm{GSH}$ 의 평균값이 
낮아져 있으며, 세포간 $\mathrm{GSH}$ 의 분포가 매우 다양해져 세포간 $\mathrm{GSH}$ 의 분포양상이 증가하는 경향을 보인다. 이것으로 세포의 항산화능을 객관화할 수 있을 뿐만 아니라 세포의 품질을 측정 할 수 있다. 또한, 이 방법을 이용하여 항산화 기능을 가지는 물질의 효능 평가에도 활용할 수 있다. 따라서 다양한 약리활 성과 생리활성물질을 지닌 식품인 토마토의 $\mathrm{GSH}$ 회복능을 통 한 항산화 효과를 얻어진 추출물과 분획물을 통해 확인하였고, 높은 항산화능을 보인 분획의 주요성분을 분리 동정하여 토마 토 항산화효능의 지표성분으로 활용하고자 본 연구를 진행하였다.

\section{재료 및 방법}

\section{실험 재료}

본 실험에서는 2020년 7월 셀투인에서 제공된 토마토 (Lycopersicon esculentum)를 실험 재료로 사용하였다. 표본시료 (KHU_SC-2007)는 경희대학교 피부생명공학센터 천연물화학실 험실에 보관되어 있다.

\section{기기 및 시약}

기기 및 시약은 이전 실험과 동일하게 사용하였다[6].

\section{GSH 회복능을 이용한 항산화능 평가}

위 연구에 대한 재료 및 방법은 이전 실험과 동일하게 실시하 였다[7].

\section{활성물질의 분리 및 $\mathrm{LC}-\mathrm{MS} / \mathrm{MS}$ 를 이용한 정랑분석}

토마토(Lycopersicon esculentum) 액상 $4 \mathrm{~kg}$ 을 $\mathrm{MeOH} 70 \%$ 수 용액 $(68 \mathrm{~L} \times 4)$ 으로 두 차례 걸쳐 추출한 후 여과지로 여과를 하 였다. 얻어진 여액을 $45^{\circ} \mathrm{C}$ 에서 감압농축하고, 이 농축물을 물 과 ethyl acetate로 분배 추출하였으며, 물층은 다시 $n$-butanol로
분배 추출 하였다. 각 층을 감압농축하여 EtOAc (TME, $120 \mathrm{~g}$ ), $n$ - $\mathrm{BuOH}\left(\mathrm{TMB}, 245 \mathrm{~g}\right.$ ) 및 $\mathrm{H}_{2} \mathrm{O}$ (TMW, $545 \mathrm{~g}$ ) 분획을 얻었다. 화합물 1에 대한 분리 과정은 Fig. 1에서 설명하고 있다. 이를 통해 화합물 1 (5,7,3'-trihydroxy-6,4',5'-trimethoxyflavone, TME10-8 (9), $46 \mathrm{mg}, \mathrm{Ve} / \mathrm{Vt} 0.417-0.505, \mathrm{R}_{\mathrm{f}}=0.55$ on $\mathrm{SiO}_{2}$ TLC $60 \mathrm{~F}_{254 \mathrm{~s}}$, $\left.\mathrm{CHCl}_{3}-\mathrm{MeOH}-\mathrm{H}_{2} \mathrm{O}=10: 3: 1\right)$ 을 분리 하였다. 분리한 물질에 대 한 정량분석을 위하여 LC-MS/MS (Agilent Technologies 6410 Triple Quad)를 이용하여 추출물과 TME 분획에 대한 분석을 진행하였다. 이때 사용된 Column은 역상 Column인 Chromasil $\mathrm{C} 18(3.0 \mathrm{~mm} \times 150 \mathrm{~mm}, 3.0 \mu \mathrm{m})$ 을 사용하였다. 이동상 용매는 $0.1 \%$ formic acid가 포함된 수용액 (A)와 $0.1 \%$ formic acid가 포함된 Acetonitrile (B)이며 이동상의 유속은 $0.4 \mathrm{~mL} / \mathrm{min}$, 주입 량은 $5 \mu \mathrm{L}$ 이었다. 이동상 기울기 조건은 $\mathrm{A}: \mathrm{B}=95: 5$ 에서 $\mathrm{B}$ 를 $100 \%$ 로 30 분간 진행하고, $30-32$ 분간 $\mathrm{B}$ 를 $100 \%$ 로 유지하였다. 분리된 화합물을 메탄올에 용해시켜 표준용액을 제조 하였으며, 정량분석의 범위는 $0.25-1.00 \mu \mathrm{g} / \mathrm{mL}$ 사이의 5 농도에서 검량곡 선을 작성하였다.

화합물 1 (5,7,3'-trihydroxy-6,4',5'-trimethoxyflavone): Yellow amorphous powder $\left(\mathrm{MeOH}-\mathrm{H}_{2} \mathrm{O}\right)$; m.p $232-235^{\circ} \mathrm{C} ;[\alpha]_{\mathrm{D}}=-11.7$, $c=1.0, \mathrm{MeOH})$; pos. FAB/MS $m / z: 361[\mathrm{M}+\mathrm{H}]^{+},{ }^{1} \mathrm{H}-\mathrm{NMR}$ $\left(600 \mathrm{MHz}\right.$, pyridine- $\left.d_{5}, \delta_{\mathrm{H}}\right): 7.65\left(1 \mathrm{H}, \mathrm{d}, J=2.4 \mathrm{~Hz} \mathrm{H}-2^{\prime}\right)$, $7.23\left(1 \mathrm{H}, \mathrm{d}, J=2.4 \mathrm{~Hz}, \mathrm{H}-6^{\prime}\right), 7.05(1 \mathrm{H}, \mathrm{s}, \mathrm{H}-3), 6.88(1 \mathrm{H}$, s. H-8), $3.98\left(3 \mathrm{H}, \mathrm{s}, 6-\mathrm{OCH}_{3}\right), 3.95\left(3 \mathrm{H}, \mathrm{s}, 4{ }^{\prime}-\mathrm{OCH}_{3}\right), 3.87$ $\left(3 \mathrm{H}, \quad \mathrm{s}, \quad 3^{\prime}-\mathrm{OCH}_{3}\right) ;{ }^{13} \mathrm{C}-\mathrm{NMR} \quad\left(150 \mathrm{MHz}\right.$, pyridine- $\left.d_{5}, \delta_{\mathrm{C}}\right)$ : 184.38 (C-4), 165.47 (C-2), 160.14 (C-7), 155.58 (C-3'), 155.29 (C-5), 155.00 (C-5'), 153.84 (C-9), 142.25 (C-4'), 133.89 (C-6), 128.62 (C-1'), 110.60 (C-2'), 106.71 (C-10), 106.37 (C-3), 103.72 (C-6'), 95.50 (C-8), $61.72 \quad\left(6-\mathrm{OCH}_{3}\right)$, $61.49\left(4^{\prime}-\mathrm{OCH}_{3}\right), 57.47\left(3^{\prime}-\mathrm{OCH}_{3}\right)$.

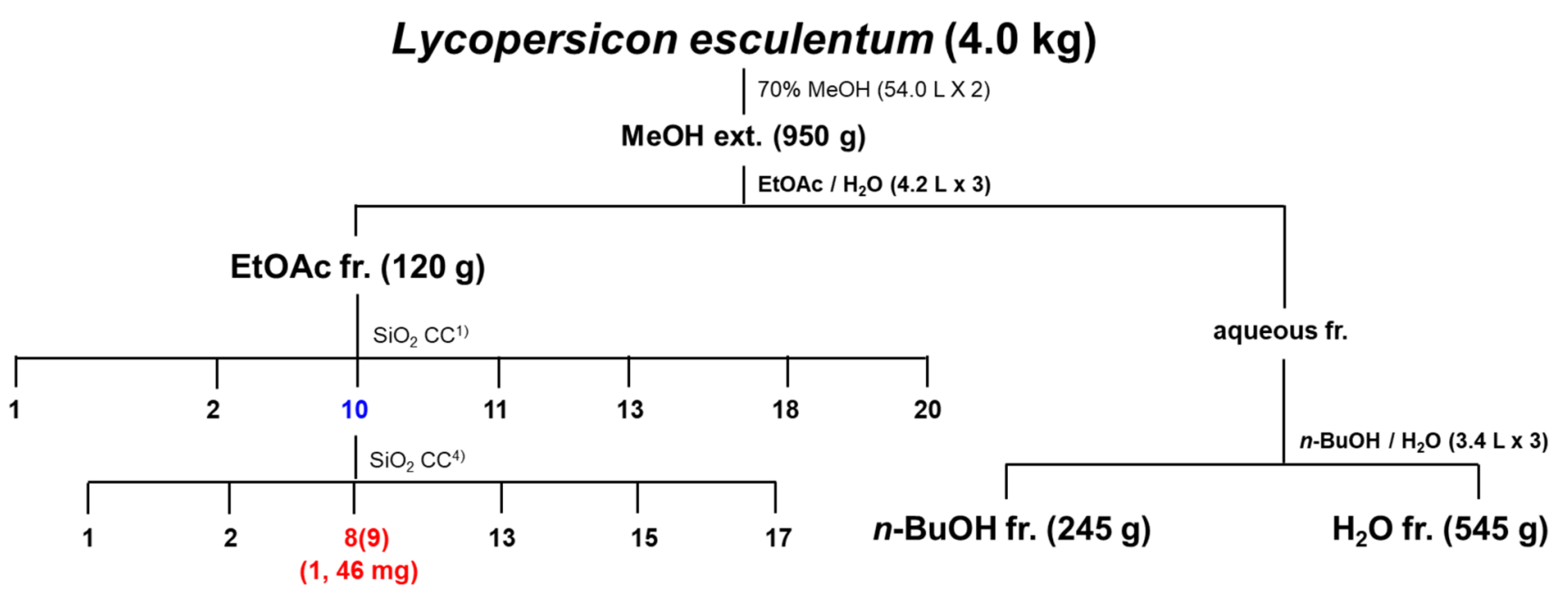

1) $\varnothing 5 \times 22 \mathrm{~cm} / n$-hexane-EtOAc=10:1 $\rightarrow 5: 1 \rightarrow 3: 1 \rightarrow 1: 1 \rightarrow \mathrm{CHCl}_{3}-\mathrm{MeOH}=10: 1 \rightarrow 7: 1 \rightarrow 5: 1 \rightarrow 3: 1 \rightarrow 2: 1 \rightarrow 1: 1$

2) $\varnothing 4 \times 13 \mathrm{~cm} / \mathrm{CHCl}_{3}-\mathrm{MeOH}=7: 1$

Fig. 1 Isolation procedures of compound 1. fr.: fraction; $\mathrm{CC}$ : column chromatography; $\mathrm{SiO}_{2}$ : silica gel; ODS: octadecyl silica gel 
(A)

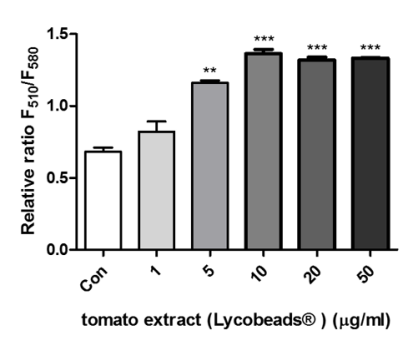

GH

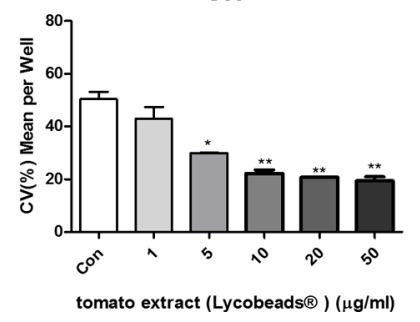

(B)

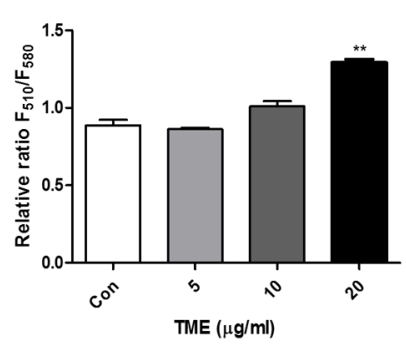

$\mathrm{GH}$



(C)

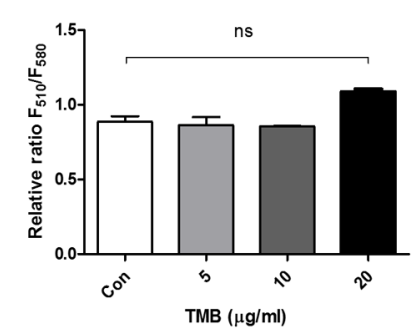

$\mathrm{GH}$

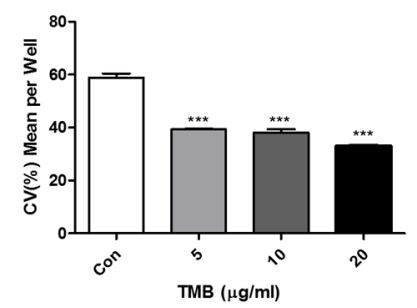

(D)

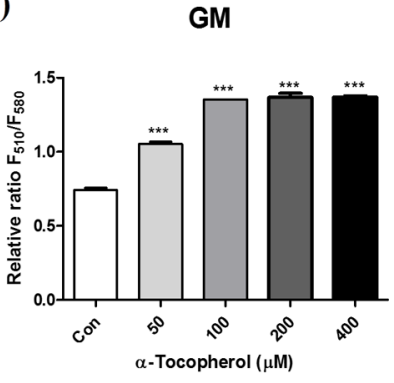

GH

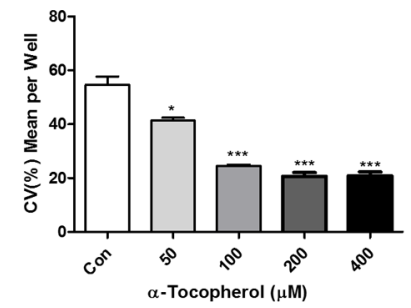

Fig. 2 Evaluation of antioxidative activity using GM and GH after treatment with extracts of tomato (A), EtOAc (TME) (B) and $n$-BuOH (TMB) (C) fractions from tomato (Lycobeads $($ ) extract, and $\alpha$-Tocopherol (D). GSH recovery capacity assay of samples were performed in concentration dependent manner. Results are presented as mean \pm SEM. ${ }^{*} p \leq 0.05,{ }^{*} p \leq 0.01,{ }^{* * *} p \leq 0.001$ compared with control. Con: non-treated (control) group

\section{결과 및 고찰}

\section{토마토(Lycopersicon esculentum) 추출, 분흭물에서의 항산화능 평가}

토마토 추출물의 항산화 활성을 알아보기 위해 추출물을 5,10 , $20 \mu \mathrm{g} / \mathrm{mL}$ 농도 별로 처리하여 GSH recovery effect 를 확인하 였다(Fig. 2A). 그 결과 토마토 추출물은 $5 \mu \mathrm{g} / \mathrm{mL}$ 농도에서 glutathione mean $(\mathrm{GM}) 1.15 \pm 0.03$ 로 대조군 $(0.67 \pm 0.03)$ 대비 $70.60 \%$ 의 증가를 보였다. 또한, glutathione heterogeneity $(\mathrm{GH})$ 도 같은 농도에서 $29.95 \pm 0.07$ 으로 대조군(50.36 \pm 2.78$)$ 대비 $40.5 \%$ 감소하여 높은 $\mathrm{GSH}$ recovery effect 를 나타내었다. 10 , $20 \mu \mathrm{g} / \mathrm{mL}$ 농도에서도 모두 유의미한 $\mathrm{GM}$ 의 증가와 $\mathrm{GH}$ 의 감소 가 유지되었다(Fig. $2 \mathrm{~A})$. 추출물 계통분획을 통해 $\mathrm{EtOAc}$ (TME), $n$ - $\mathrm{BuOH}$ (TMB), $\mathrm{H}_{2} \mathrm{O}$ (TMH) fraction을 얻은 뒤에 $\mathrm{TME}, \mathrm{TMB}$ 의 $\mathrm{GSH}$ 회복능을 평가하였다. TME 분획은 20 $\mu \mathrm{g} / \mathrm{mL}$ 농도에서 $\mathrm{GM} \quad 1.29 \pm 0.02$ 로 대조군 $(0.89 \pm 0.04)$ 대비 $44.91 \%$ 의 증가를 보였고, $\mathrm{GH}$ 에서는 $\mathrm{TMB}$ 와 마찬가지로 $5 \mu \mathrm{g}$ $\mathrm{mL}$ 만 처리해도 $40.22 \pm 0.38$ 로 대조군 $(58.90 \pm 1.51)$ 대비 $31.70 \%$ 감소하였다. $\mathrm{TMB}$ 분획의 경우, $20 \mu \mathrm{g} / \mathrm{mL}$ 농도에서 $\mathrm{GM}$ $1.10 \pm 0.03$ 로 대조군 $(0.88 \pm 0.03)$ 대비 $22.51 \%$ 의 증가를 보였으나 통계적으로 유의미하지 않은 차이였고, $\mathrm{GH}$ 에서는 $5 \mu \mathrm{g} / \mathrm{mL}$ 만 처리해도 $39.32 \pm 0.25$ 으로 대조군 $(58.89 \pm 1.50)$ 대비 $33.30 \%$ 감 소하여 세포 간 균질성이 향상되는 것을 확인하였다(Fig. 2B). 이를 통해 TMB보다 TME가 통계적인 차이를 보이며 더 $\mathrm{GSH}$ recovery effect 를 향상시키는 것으로 나타났다(Fig. 2B).

TME로부터 $\mathrm{SiO}_{2} \mathrm{CC}(\varphi 5 \times 22 \mathrm{~cm}, n$-hexane-EtOAc $=10: 1$ $\rightarrow 5: 1 \rightarrow 3: 1 \rightarrow 1: 1 \rightarrow \mathrm{CHCl}_{3}: \mathrm{MeOH}=10: 1 \rightarrow 7: 1 \rightarrow 5: 1 \rightarrow 3: 1 \rightarrow 2: 1 \rightarrow$ $1: 1$ )를 실시하여 21 개의 분획물(TME-1 TME-21)을 얻어 위 실 험과 동일하게 GSH recovery effect 를 평가하였다(Fig. 3). 그
결과 TME-3과 10 은 특정 처리농도에서 GSH recovery effect 가 향상되었다(Fig. $3 \mathrm{~A}$ ). TME-3는 $20 \mu \mathrm{g} / \mathrm{mL}$ 에서 $\mathrm{GM} 1.12 \pm 0.03$ 으로 대조군 $(0.85 \pm 0.02)$ 대비 $31.82 \%$ 증가했고, $\mathrm{GH}$ 도 같은 농 도에서 $33.01 \pm 3.71$ 로 대조군 $(46.97 \pm 0.06)$ 대비 $29.69 \%$ 감소하 였다. TME- 10 의 경우, $5 \mu \mathrm{g} / \mathrm{mL}$ 에서 $\mathrm{GM} 1.15 \pm 0.02$ 로 대조군 $(0.86 \pm 0.01)$ 대비 $33.70 \%$ 증가했고, $\mathrm{GH}$ 도 같은 농도에서 $22.99 \pm 0.13$ 으로 대조군 $(41.31 \pm 1.21)$ 대비 $44.31 \%$ 감소하여 높은 GSH recovery effect 를 나타내었다.

위 결과를 통하여 $\mathrm{TME}-10$ 이 $5 \mu \mathrm{g} / \mathrm{mL}$ 이하에서도 세포 내 $\mathrm{GSH}$ recovery effect 를 향상시키는 데에 도움을 준다는 것을 발견하였다. 이를 바탕으로 TME-10 (1.1 g)에 대하여 $\mathrm{SiO}_{2} \mathrm{CC}$ ( $\varphi 4 \times 13 \mathrm{~cm}, \mathrm{CHCl}_{3}-\mathrm{MeOH}=7: 1$ )를 실시하여, 17 개의 분획물 (TME-10-1 TME-10-17)을 얻었다. 이중 TME-10-8 (9), TME10-12 (26), TME-10-13 (34), TME-10-13 (37)의 4가지 단일 물질을 동일한 방법으로 $1,5,10,20 \mu \mathrm{g} / \mathrm{mL}$ 농도 별로 처리하 여 $\mathrm{GSH}$ 회복능을 측정하였다. 이 중 $\mathrm{TME}-10-8(9)$ 의 경우, 5 $\mu \mathrm{g} / \mathrm{mL}$ 에서 $\mathrm{GM} 1.31 \pm 0.01$ 으로 대조군 $(0.68 \pm 0.01)$ 대비 $92.62 \%$

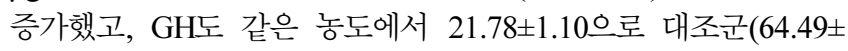
0.76 ) 대비 $66.21 \%$ 감소하여 비교 그룹 중 가장 높은 $\mathrm{GSH}$ recovery effect 를 나타내었다(Fig. 4).

\section{활성물질 동정 및 LC-MS/MS를 이용한 정량분석}

항산화 활성이 가장 높았던 단일물질인 TME-10-8 (9)에 대하 여 Nuclear magnetic resornance (NMR), infrarad spectroscopy (IR), $\mathrm{FAB} / \mathrm{MS}$ 를 측정하여 구조동정을 실시하였다. 화합물 1 은 flavone 화합물로 TLC 확인시 UV $(254 / 365 \mathrm{~nm})$ 에서 UV 흡수 를 보였으며, $10 \% \mathrm{H}_{2} \mathrm{SO}_{4}$ 발색 시 노란색으로 발색 되었다. positive $\mathrm{FAB} / \mathrm{MS}$ 에서 $m / z 361[\mathrm{M}+\mathrm{H}]^{+}$분자이온 peak가 관측 되어 분자량을 360 로 확인하였다. IR spectrum으로부터 공역화 
(A)

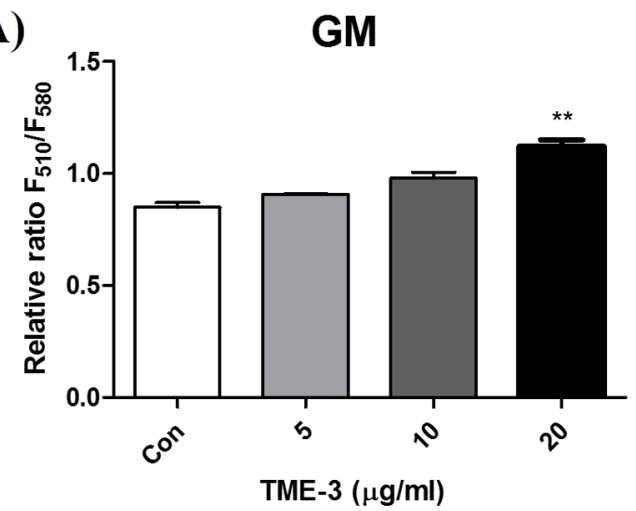

(B)

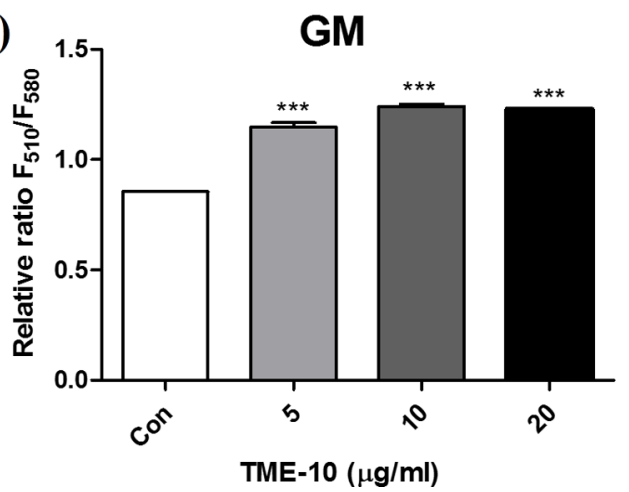

GH

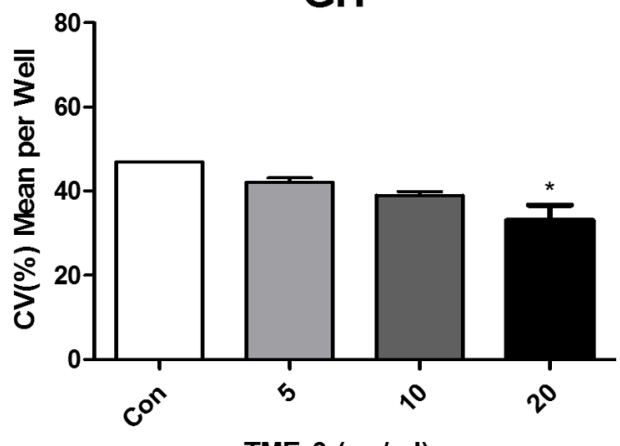

TME-3 $(\mu \mathrm{g} / \mathrm{ml})$

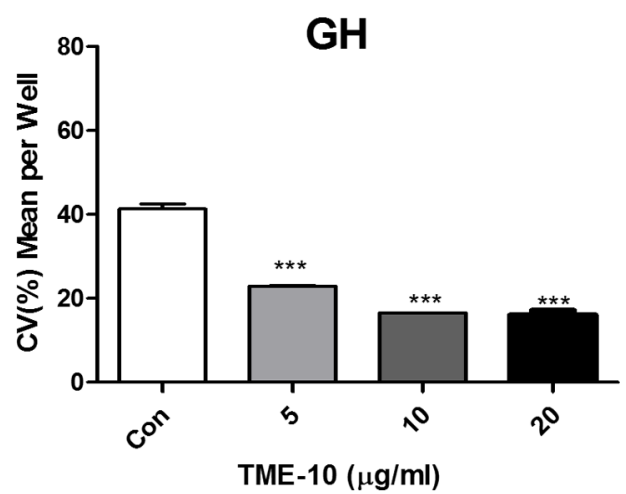

Fig. 3 Evaluation of antioxidative activity using GM and GH after treatment with TME-3 (A) and 10 (B) of EtOAc (TME) fraction from tomato extract. GSH recovery capacity assay of samples were performed in concentration dependent manner. Results are presented as mean $\pm \mathrm{SEM}$. $* p \leq 0.05$, ${ }^{* *} p \leq 0.01,{ }^{* * *} p \leq 0.001$ compared with control. Con: non-treated (control) group

(A)

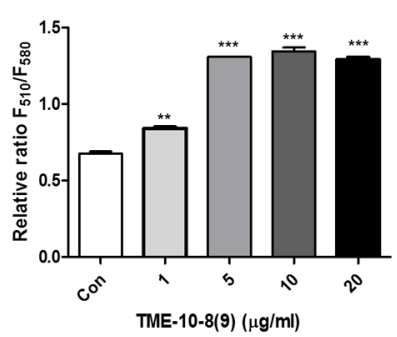

GH

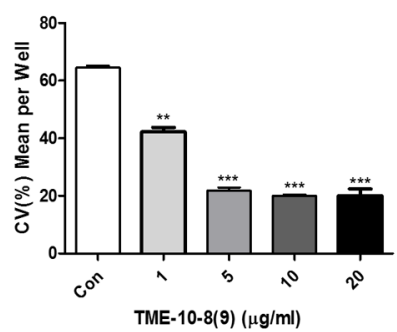

(B)

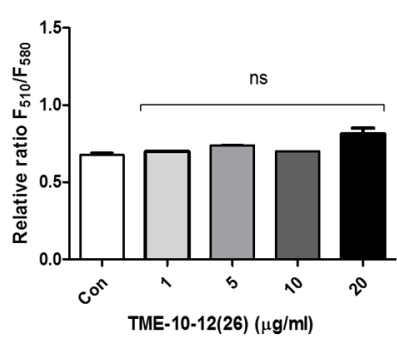

GH

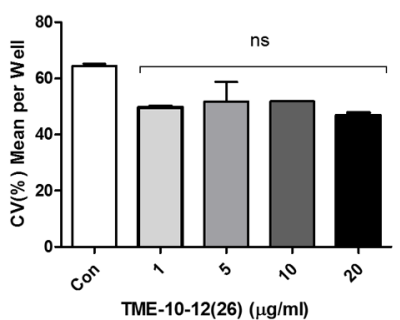

(C)

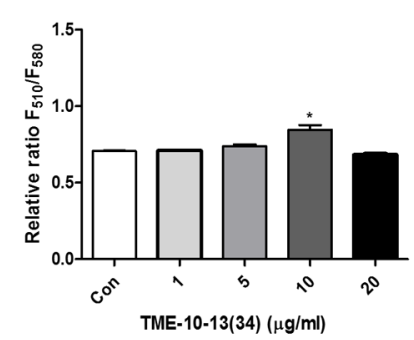

GH

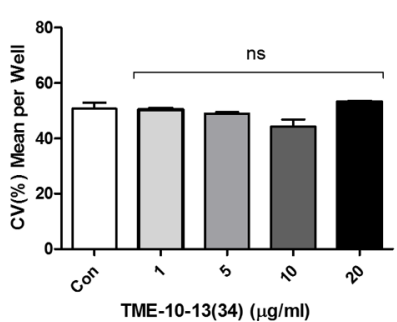

(D)

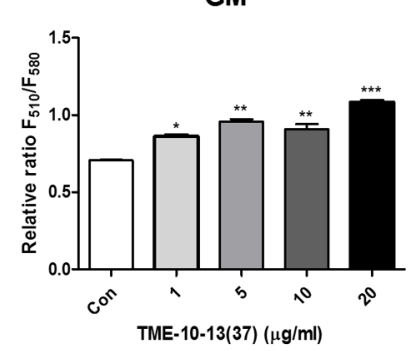

GH

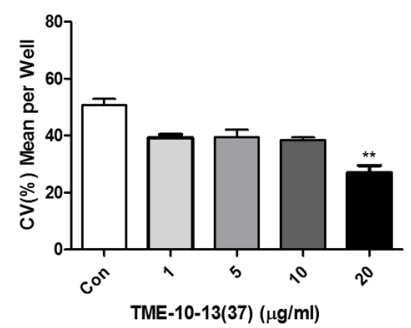

Fig. 4 Evaluation of antioxidative activity using GM and GH after treatment with 4 frations of TME-10 from tomato extract. GSH recovery capacity assay of 4 frations of TME-10 were performed in concentration dependent manner. Results are presented as mean \pm SEM. ${ }^{*} p \leq 0.05$, ${ }^{* *} p \leq 0.01$, ${ }^{* * *} p \leq 0.001$ compared with control. Con: non-treated (control) group 
<smiles>COc1cc(-c2cc(=O)c3c(O)c(OC)c(O)cc3o2)cc(O)c1OC</smiles>

Fig. 5 Chemical structure of compound 1 from the Lycopersicon esculentum

된 카보닐기 $\left(1613 \mathrm{~cm}^{-1}\right)$, 수산기 $\left(3356 \mathrm{~cm}^{-1}\right)$ 와 이중결합(1580 $\left.\mathrm{cm}^{-1}\right)$ 이 있는 것으로 확인되었다. ${ }^{1} \mathrm{H}-\mathrm{NMR}(600 \mathrm{MHz}$, pyridine$\left.d_{5}, \delta_{\mathrm{H}}\right)$ spectrum에서 2 개의 olefin methine proton signal 7.65 $\left(1 \mathrm{H}, \mathrm{d}, J=2.4 \mathrm{~Hz} \mathrm{H}-2^{\prime}\right), 7.23\left(1 \mathrm{H}, \mathrm{d}, J=2.4 \mathrm{~Hz}, \mathrm{H}-6^{\prime}\right)$ 를 통 해 1,2,4-trisubstituted benzene 구조가 존재함을 예상하였다. 또 한 2개의 olefin methine proton signal $7.05(1 \mathrm{H}, \mathrm{s}, \mathrm{H}-3)$, 6.88 (1H, s. H-8)을 통해 1,2,3,4,5-pentasubstituted benzene 구조가 존재함을 예상하였다. 이를 통해 이 화합물이 flavone 화합물임을 예상하였다. 또한 3개의 methoxy proton signal $3.98\left(3 \mathrm{H}, \mathrm{s}, 6-\mathrm{OCH}_{3}\right), 3.95\left(3 \mathrm{H}, \mathrm{s}, 4{ }^{\prime}-\mathrm{OCH}_{3}\right), 3.87(3 \mathrm{H}, \mathrm{s}$, $\left.3^{\prime}-\mathrm{OCH}_{3}\right)$ 을 관측하였다. ${ }^{13} \mathrm{C}-\mathrm{NMR}\left(150 \mathrm{MHz}\right.$, pyridine- $\left.d_{5}, \delta_{\mathrm{C}}\right)$ spectrum에서 3 개의 methoxy carbon signal [ $\delta_{\mathrm{C}} 61.72$ (6$\left.\left.\mathrm{OCH}_{3}\right), 61.49\left(4^{\prime}-\mathrm{OCH}_{3}\right), 57.47\left(3^{\prime}-\mathrm{OCH}_{3}\right)\right]$ 을 제외하고 탄소수 가 15 개임을 확인하였고, 이를 통해 flavone임을 확인하였다. 1 개의 conjugated ketone carbon signal $\left(\delta_{\mathrm{C}} 184.38\right)$, 8개의 oxygenated olefin quaternary carbon signal $\left(\delta_{\mathrm{C}} \quad 165.47\right.$;
$160.14 ; 155.58 ; 155.29 ; 155.00 ; 153.84 ; 142.25 ; 133.89)$ 을 확 인하였고, 2 개의 olefin quaternary carbon signal $\left(\delta_{\mathrm{C}} 128.62\right.$; 106.71)을 확인하였으며, 4개의 olefin methine carbon signal $\left(\delta_{\mathrm{C}} 110.60 ; 106.37 ; 103.72 ; 95.50\right)$ 을 확인하였다. 위의 data 를 문헌값[8]과 비교하여 화합물 1을 5,7,3'-trihydroxy-6,4',5'trimethoxyflavone 으로 구조 동정 하였다(Fig. 5).

화합물 1 의 정량분석을 위해 LC-MS/MS를 사용하여 크로마 토그램을 분석하였다. 최적의 용매 기울기 조건을 확립하고 분 석된 결과의 머무름 시간(RT)을 비교하였을 때, 화합물 1은 7.85 분에서 검출되었다(Fig. 6). 검량 곡선( $\mathrm{y}=72,770.1869 \mathrm{x}+$ $12,519.4791)$ 은 표준물질의 5 농도 범위 안에서 측정된 값을 회 기 분석을 통해 작성하였다. 상관계수 $\left(\mathrm{r}^{2}\right)$ 는 0.9992 로 매우 높은 값을 보여주었다. 화합물 1 의 함량분석 결과, 추출물에서 $0.96 \pm 0.03 \mu \mathrm{g} / \mathrm{mg}$ 그리고 $\mathrm{TME}$ 분획에서 $4.02 \pm 0.12 \mu \mathrm{g} / \mathrm{mg}$ 으로 확인되었다. 추출물과 분획물에서의 높은 함량은 토마토의 항산 화능에 화합물 1의 높은 기여도를 보여준다.

Flavone은 다양한 문헌에서 항산화 활성, 항염 활성, 당뇨 활 성 [8,9] 등이 보고되어 있다. 따라서 토마토 추출물과 분획물에 서의 높은 GSH 회복능 또한 주요화합물 중 하나인 5,7,3'trihydroxy-6,4',5'-trimethoxyflavone 에 의한 영향이 있음을 알 수 있다. 또한, 이와 같은 결과로 토마토가 항산화능을 가지는 건강식품소재로서 사용할 수 있는 가능성을 확인하였다.

초 록

토마토 액상을 $70 \% \mathrm{MeOH}$ 수용액으로 추출하고, 얻어진 추출 물을 $\mathrm{EtOAc} n-\mathrm{BuOH}$ 및 물로 용매 분획 하였다. 이 중 활성 이 확인된 ethyl acetate (EtOAc) 분획으로부터 silica gel $\left(\mathrm{SiO}_{2}\right)$ 과 octadecyl silica gel column chromatography로 정제하

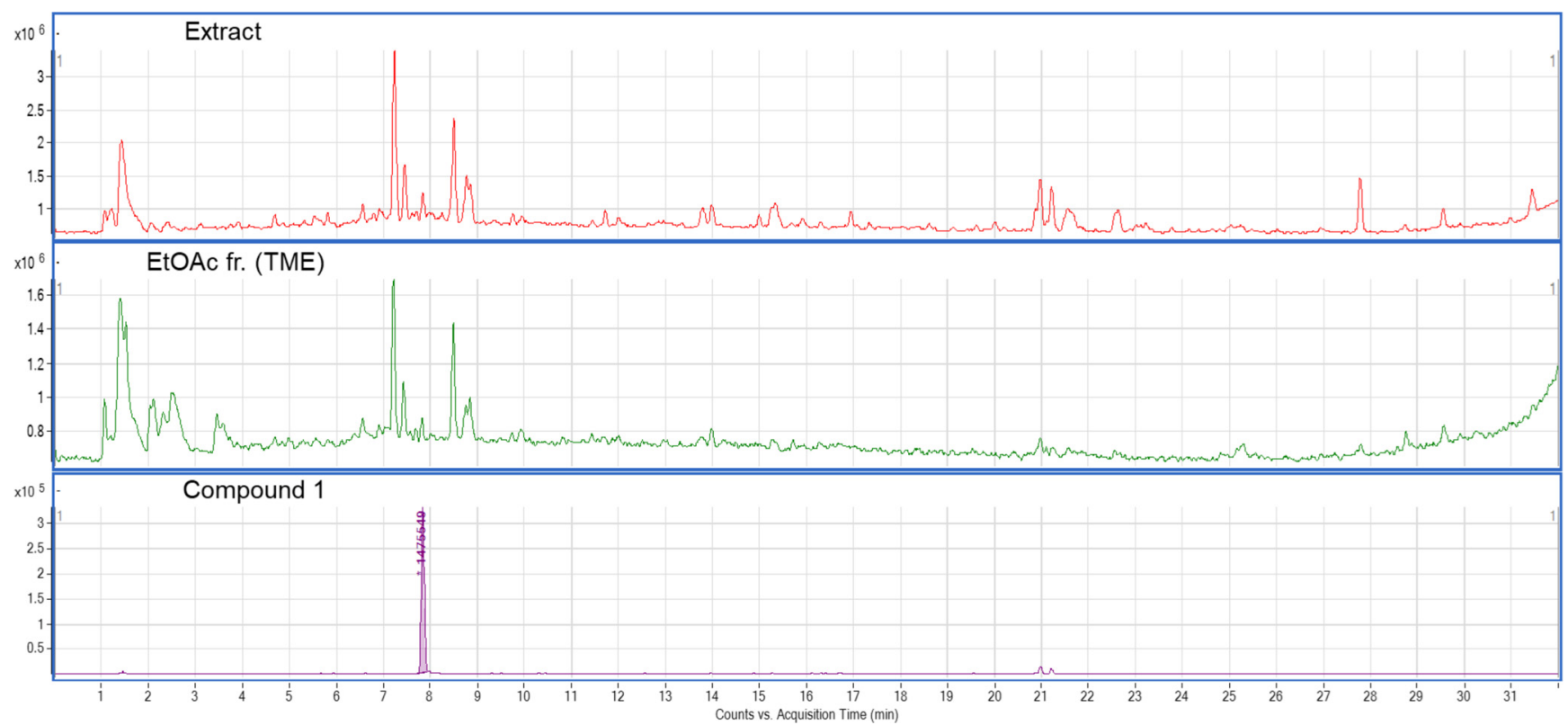

Fig. 6 TIC chromatograms from the extract of Lycopersicon esculentum, EtOAc fraction (TME), and compound 1 
여 1종의 화합물을 분리 하였다. Nuclear magnetic resornance, mass spectroscopy 및 infrarad spectroscopy 등의 스텍트럼 데 이터를 통해 화합물 1의 화학구조를 $5,7,3^{\prime}$-trihydroxy-6,4',5'trimethoxyflavone (1) 로 동정 하였다. 화합물 1의 함량분석 결 과, 추출물에서 $0.96 \pm 0.03 \mu \mathrm{g} / \mathrm{mg}$ 그리고 $\mathrm{EtOAc}$ 분획(TME)에서 $4.02 \pm 0.12 \mu \mathrm{g} / \mathrm{mg}$ 으로 확인되었다. 본 연구를 통해서 glutathione mean의 증가와 glutathione heterogeneity의 감소를 보인 토마토 추출물 및 분획물과 토마토 유래 화합물이 세포 내 glutathione 수준을 균일하게 올려준다는 것을 입증함으로써 항산화 효능을 확인할 수 있었다.

Keywords 토마토 · Flavone · Glutathione 회복능 · Nuclear magnetic resornance

\section{References}

1. Aneta G, Małgorzata MD (2014) Lycopene-antioxidant with radioprotective and anticancer properties. A review. Rocz Panstw Zakl Hig 65(4): 263-271

2. Jung EB, Shin MK (1990) In Hyang Yak DaeSaJun. 3rd edition. Young Lim Sa, Seoul
3. Wu G, Fang YZ, Yang S, Lupton RJ, Turner DN (2004) Glutathione metabolism and its implications for health. J Nutr 134(3): 489-492. doi: $10.1093 / \mathrm{jn} / 134.3 .489$

4. Mailloux RJ, McBride SL, Harper ME (2013) Unearthing the secrets of mitochondrial ROS and glutathione in bioenergetics. Trends Biochem Sci 38(12): 592-602. doi: 10.1016/j.tibs.2013.09.001

5. Yang SL, Yu PL, Chung KR (2016) The glutathione peroxidasemediated reactive oxygen species resistance, fungicide sensitivity and cell wall construction in the citrus fungal pathogen Alternaria alternata. Environ Microbiol 18(3): 923-935. doi: 10.1111/1462-2920.13125

6. Kim HG, Jung YS, Oh SM, Oh HJ, Ko JH, Kim DO, Kang SC, Lee YG Lee DY, Baek NI (2020) Coreolanceolins A-E, New Flavanones from the Flowers of Coreopsis lanceolata and Their Antioxidative and Antiinflammatory Effects. Antioxidants 9: 539-555. doi: 10.3390/antiox 9060539

7. Kim HG, Jeon HJ (2020) Antioxidant compound from the Lycopersicon esculentum. J Appl Biol Chem 63(4): 319-325. doi: 10.3839/jabc. 2020.042

8. Ko JH, Nam YH, Joo SW, Kim HG, Lee YG, Kang TH, Baek NI (2018) Flavonoid 8-O-Glucuronides from the Aerial Parts of Malva verticillata and Their Recovery Effects on Alloxan-Induced Pancreatic Islets in Zebrafish. Molecules 23:833-847. doi: 10.3390/molecules23040833

9. Maleki SJ, Crespo JF, Cabanillas B (2019) Anti-inflammatory effects of flavonoids. Food Chem 299: 125124. doi: 10.1016/j.foodchem.2019. 125124 